\title{
A IMPORTÂNCIA DAS MANIFESTAÇÕES CULTURAIS NAS AÇÕES DO EDUCAR EM ESPAÇOS ESCOLARES DA EDUCAÇÃO BÁSICA EM FEIRA DE SANTANA \\ Evelly de Mônaco Silva soares ${ }^{1}$; Miguel Almir Lima de Araújo ${ }^{2}$ \\ 1. Bolsista PIBIC/FAPESB, Graduando em pedagogia, Universidade Estadual de Feira de Santana, e-mail: evellymonacosoares95@gmail.com \\ 2. Orientador, Departamento de Educação, Universidade Estadual de Feira de Santana, e-mail: malmir2@gmail.com
}

PALAVRAS-CHAVE: Cultura/s regionais/locais - Ações do educar -- Educação Básica

\section{INTRODUÇÃO}

Este trabalho faz parte de uma pesquisa interinstitucional, intitulada "Coexistência entre cultura/s e educação: a relevância dos repertórios simbólicos da/s Cultura/s, da diversidade cultural no cotidiano da educação escolar", que teve início em 2015 pelo Núcleo de Investgações Transdisciplinares -- NIT da Universidade Estadual de Feira de Santana. As investigações da pesquisa partiram de indagações que se propuseram identificar como estão sendo tecidas as relações entre Culturas/s e Educação escolar nos diversos contextos em que foi desenvolvida, com destaque na temática da diversidade cultural buscando compreender se essas práticas educativas estão se atentando apenas aos chamados saberes universais ou se estão considerando também os contextos socioculturais dos seus protagonistas, a diversidade dos repertórios culturais (regionais e locais) que os constituem.

Partindo das conjecturas de que Cultura/s e Educação são fenômenos coexistentes, de que a diversidade cultural, os conteúdos e formas das culturas locais e regionais, com suas vertentes, também são essenciais nos processos de formação humana, do cuidado com a cidadania. O presente resumo apresenta os dados sedimentados durante a execução do plano de trabalho. Por muito tempo, pesquisas acadêmicas que abordam o campo das Culturas regionais/locais como lócus de estudo e discussão foram secundarizadas devido à supremacia das tendências que são predominantes no conhecimento científico que negam a relevância destas Culturas.

A pesquisa teve como objetivo identificar a importância da relação entre Cultura/s e Educação, e se as manifestações culturais regionais/locais estão presentes nos espaços escolares, considerando os repertórios simbólicos e singulares destas localidades. Procuro refletir sobre a relevância dessas manifestações nas ações do educar em duas escolas da Educação Básica uma de Feira de Santana e outra no distrito de Caldeirão localizado do Município de Araci.

Considero cultura regional/local as expressões específicas e contextuais de cada grupo ou comunidade, de cada localidade ou região, que apresentam características singulares referentes aos saberes e fazeres que constituem os hábitos, crenças e valores de seus sujeitos.

A pesquisa desenvolvida tentou apontar a importância das expressões significativas das Cultura/s regionais/locais nos espaços escolares da Educação Básica. Devido a uma significativa ausência de estudos voltados para essa temática, justifico esta pela atualidade do tema e da necessidade de compreender como essas expressões culturais podem contribuir nas ações do educar colaborando no processo ensino e aprendizagem dos/as alunos/as da Educação Básica. 


\section{MATERIAL E MÉTODOS OU METODOLOGIA (ou equivalente)}

A abordagem metodológica escolhida dessa pesquisa foi a qualitativa que visa a elaboração de uma descrição e interpretação partindo do contato direto com as experiências vividas pelos sujeitos. Desta forma, o processo de compreensão dos fenômenos culturais nas ações do educar ocorre dentro do universo das práticas cotidianas e dos valores dos sujeitos investigados. Nas pesquisas qualitativas as categorias de análise devem ser constituídas de modo mais flexível e melhor aprimoradas no decurso da trajetória investigativa.

Através dos dispositivos de investigação utilizados para construção dos dados, busco compreender a importância das expressões culturais nas ações do educar em espaços escolares da educação básica, bem como se há mais presença ou ausência dessa situação. Os instrumentos utilizados foram: a observação participante, a entrevista aberta que se traduz na escuta cuidadosa, aberta e flexível dos depoimentos dos protagonistas das ações de maneira agradável e descontraída, o questionário aberto, bem como os registros fotográficos e as filmagens. Realizei anotações de diversas experiências vividas, entre outros procedimentos que se fizerem pertinentes. $O$ questionário aberto foi aplicado a professores/as e estudantes mediante a aquiescência destes. Através da observação participante foi viabilizado uma relação mais próxima com os sujeitos pesquisados em que me adentrei no cotidiano do fenômeno investigado garantindo uma melhor qualidade na interpretação e na compreensão dos dados. Para a realização desta pesquisa recorri aos seguintes recursos: Papel de oficio (A4); máquina fotográfica; lápis; canetas; gravador; cadernos de anotações; mídias (CD, DVD, Pen drive), filmadora e câmera fotográfica.

Os sujeitos da pesquisa foram constituídos de doze (12) alunos e quatro (04) professores/as de duas escolas Municipais da Educação Básica de Feira de Santana e de Araci-BA que responderam ao convite realizado pelo NIT. As datas e os horários para realização dos encontros com os sujeitos foram discutidas com os participantes por vários veículos de comunicação.

\section{RESULTADOS E/OU DISCUSSÃO (ou Análise e discussão dos resultados)}

A primeira etapa é foi constituída pela observação e análise e serão apresentadas nesse. Faz parte da segunda etapa da pesquisa os resultados propostos no plano de trabalho para a comunidade foram os seguintes: Realização de um seminário nas escolas apresentando os resultados da pesquisa; mostra de fotografia dos momentos relevantes da pesquisa; montagem de um vídeo; e apresentação dos resultados das análises de dados em eventos institucionais de iniciação científica.

Como resultados da pesquisa apresento as contribuições relevantes e para os processos educacionais nos locais onde a pesquisa foi realizada, bem como o processo formativo.

No primeiro encontro com os professores e gestores das instituições explicitamos a natureza da pesquisa e a sua importância para a comunidade escolar.

A relevância dos saberes e sentires, das expressões da cultura local no cotidiano da ação de educar na escola/comunidade para os estudantes, se estes saberes e sentires, estas expressões da cultura local estão presentes no cotidiano das ações de educar desta por fim, se estas expressões da cultura local podem e devem estar mais presentes no cotidiano da escola/comunidade?

A maioria realçou que é importante a presença destes saberes e sentires, das expressões da cultura local no cotidiano da ação de educar na escola/comunidade haja vista a possibilidade de reforço da identidade cultural local/regional para a localidade. Percebi através das falas dos entrevistados que práticas pedagógicas e culturais não podem estar 
dissociadas, estas devem ser campos interligados, proporcionando um pensar crítico e vasto, destacando os valores e sentidos humanos, inerentes às múltiplas expressões culturais, que constituem o viver cotidiano dos sujeitos da educação. Nessa perspectiva, as manifestações culturais, possibilitam experiências com a sensibilidade, a imaginação, com o desenvolver do espírito inventivo, emancipador e transformador. Por tal motivo, é importante considerar a presença da cultura regional/local nas práticas educativas, principalmente nas abordagens sobre a pluralidade cultural, realçando, assim, a diversidade e singularidades presentes na região na qual a escola se encontra. Sendo assim, diante das falas dos alunos percebi que estes acham importante a presença das manifestações culturais da comunidade nas ações do cotidiano da escola. Mesmo a escola promovendo espaço de socialização de diversas culturas, alguns alunos afirmaram que ainda existem lacunas quanto à inserção dessas ações no dia-a-dia da sala de aula.

(CANDAU, 2003, p. 161) afirma que "a escola sempre teve dificuldade em lidar com a pluralidade e a diferença. Tende a silenciá-las e neutralizá-las. Sente-se mais confortável com a homogeneização e a padronização" Abrir espaços para a diversidade, a diferença, e para o cruzamento de culturas constitui um grande desafio que está sendo chamado para o enfrentamento. Ao invés de conservar uma tradição monocultural, a escola está sendo convidada a lidar com a pluralidade de culturas, adotar os diferentes indivíduos socioculturais presentes em seu contexto, abrir espaços para a manifestações das culturas locais/regionais e valorização das diferenças.

Foi realçado, através das falas, que as manifestações se limitam às datas comemorativas compostas no calendário anual como a semana do Folclore, os festejos juninos, o dia do Índio, o dia da consciência negra entre outros. Diante desse contexto, foi relatado e compreendido que manifestações artístico-culturais devem está mais presentes nas ações do educar, porque quando as práticas educativas não se apropriam dos saberes e sentires mais próximos e contextuais de cada grupamento ou comunidade, estas projetam, em suas formas e conteúdos, apenas os saberes e sentires de contextos socioculturais alheios e distantes, os repertórios considerados universais. Confinado apenas nessa perspectiva, o educar se descontextualiza e passa a se configurar como ação rígida e alienante com seu perfil uniformizador e domesticador. Desvinculada dos contextos culturais mais locais e regionais, as práticas educativas tendem a desqualificar os repertórios de crenças, valores que traduzem a identidade e diversidade de cada povo propagando concepções daquilo que consideram ser suas verdades apresentadas como únicas e inquestionáveis (DAYRELL, 1996; SODRÉ, 2102).

\section{CONSIDERAÇÕES FINAIS}

Desde os repertórios construídos na pesquisa considero que as manifestações culturais regionais/locais nas ações do educar nos espaços escolares visitados têm apresentado significativas contribuições para o processo de ensino e aprendizagem e na afirmação das identidades dos alunos. Todavia, percebi que ainda existem passos a serem dados para uma melhor inserção dessas manifestações no cotidiano da sala de aula. É necessário ir além dos momentos conhecidos como "mostra cultural" ou "feira de cultura" os quais muitas vezes acontecem anualmente.

Considero que a cultura tem um importante papel no processo de aprendizagem pois esta possibilita além da socialização, a afirmação da identidade cultural e discussões sobre os diferentes saberes no espaço escolar por meio dos conteúdos culturais. e essas mudanças devem acontecer através de algumas modificações do currículo. $\mathrm{O}$ ensino baseado nas expressões culturais tem esse poder de agrupar os diferentes conhecimentos e levá-los a discussões em sala de aula. Mas para que isso ocorra faz-se necessário a 
capacitação dos professores e ações conjuntas para que se possa ter um novo olhar sobre a relação entre Culturas e educação cultura na sala de aula.

Por fim, a cultura é um elemento crucial no processo de ensino-aprendizagem e a escola deve integrá-lo em seu cotidiano inserindo-a nos currículos escolares. Outras atividades precisam ser desenvolvidas no âmbito escolar para que haja momentos de socialização dos alunos através dos seus saberes e valores próprios dialogando com saberes universais

\section{REFERÊNCIAS BIBLIOGRÁFICAS}

Os sentidos da arte. Coexistência entre arte e educação. Caderno de Educação, n. 4, p. 37-54. Jan/jun. Feira de Santana, 2001.

BHABHA, Homi K. O local da cultura. Belo Horizonte: Ed. UFMG, 2003.

DAYRELL, Juarez (Org.). Múltiplos olhares sobre educação e cultura. Belo Horizonte: Ed. UFMG, 1996.

CANDAU, Vera Maria Ferrão. Educação escola e Cultura(s): construindo caminhos. Revista Brasileira de Educação, 2003.

DUARTE JR, João Francisco. Por que Arte-Educação ? 22 ${ }^{\mathrm{a}}$ ed. Campinas,SP: Papirus,2012.

FRIEDMANN, Adriana. Brincar: crescer e aprender- O resgate do jogo infantil. São Paulo: Moderna, 1996.

FORQUIN, Jean-Claude. Escola e cultura: as bases sociais e epistemológicas do conhecimento escolar. Porto Alegre: Artes Médicas, 1993.

FREIRE, Paulo. Pedagogia da autonomia: saberes necessários à prática educativa. Rio de Janeiro: Paz e Terra, 1996.

GIROUX, Henri. Cruzando as fronteiras do discurso educacional. Porto Alegre: Artes Médicas, 1999.

HALL, Stuart. A Centralidade da Cultura: notas sobre as revoluções culturais no nosso tempo. Educação e Realidade, Porto Alegre, v.22, n.2, jul/dez, 1997.

MORIN, Edgar. Ciência com consciência. Rio de Janeiro: Francisco Alves, 1996.

SACRISTÁN, José Gimeno. A educação obrigatória. Porto Alegre: Artmed, 2001.

SODRÉ, Muniz. Reinventando a educação: diversidade, descolonização e redes. Petrópolis, RJ: Vozes, 2012. 